\title{
Dispute over 'threshold' explosions could disrupt test ban negotiations
}

Paris. International efforts to negotiate a Comprehensive Test-Ban Treaty (CTBT) are in the balance because of proposals by nuclear weapons states to exempt low-yield nuclear explosions. Non-nuclear weapons nations seem prepared to abandon efforts to agree on a treaty altogether rather than to accept the proposals in their current form.

A comprehensive test-ban is widely considered to be the price that nuclear weapons states promised to pay earlier this year for agreement among non-nuclear states on an indefinite extension of the Nuclear NonProliferation Treaty (NPT).

But whereas the non-nuclear states have until recently seemed ready to agree to a sufficiently comprehensive ban to encourage disarmament as well as non-proliferation, they fear that the new proposals would drop disarmament from the CTBT's goals.

The controversy over the CTBT - now being negotiated at the Conference on Disarmament at Geneva - centres on closed talks among the permanent five nuclear weapons state members of the United Nation's Security Council, known as the P5. These talks are intended to fix the threshold below which explosions would be exempt from the ban, the main issue within the so-called "activities not prohibited" section of the treaty.

The official position of the United States is that only hydronuclear experiments (HNEs) with yields below $1.8 \mathrm{~kg}$ equivalent of TNT should be exempt from the ban. Such small HNEs are not very useful for designing weapons, but they are widely accepted as useful for testing the safety of stored weapons. What distinguishes HNEs from full-blown nuclear tests is that the chain reaction is stopped before a full-yield explosion occurs .

Last month, however, William Perry, the US defence secretary, announced that the United States had reopened discussions on the level of this threshold. The Pentagon has since argued that tests with yields as high as 500 tonnes should be exempt from the ban, although the White House has, for the present, rejected this proposition.

The US announcement followed a demand by France that the threshold be fixed at 200-300 tonnes. The United Kingdom, whose official position calls for a threshold of $45 \mathrm{~kg}$, is also said in some circles to be keen on raising this to 500 tonnes. "I think the hawks in the nuclear weapons states are working together on this to undo the treaty", says Christopher Paine from the Natural Resources Defense Council (NRDC), based in Washington, DC.

The proposals have been greeted with

\section{France keeps the experts guessing}

Paris. France's proposal to exempt lowyield explosions from the Comprehensive Test-Ban Treaty (CTBT) (see above), combined with its recent decision to resume nuclear testing, has provoked a vigorous debate about the goals of its nuclear weapons programme.

Jacques Chirac, the French president, has stated that one or two of the eight proposed tests are needed to qualify the TN75, a miniaturized, 100-kilotonne warhead for the M5 intercontinental ballistic missile (ICBM) designed for the next generation Triomphant-class submarines. Another two tests are needed to maintain the existing French stockpile, he says, and a further four for calibrating simulation techniques.

French officials also argue that they need a new generation of weapons that would be less "sensitive" to ageing and could be remanufactured reliably. They point out that France gets less information from its tests than the United States because of technical problems, a claim supported by reports from the US Central Intelligence Agency.

Christopher Paine, a senior research associate at the Natural Resources Defense Council (NRDC) in Washington, DC, says that France "seems to have a reasonable case" for testing the TN75 warhead. But he contests claims by France that further tests are needed to ensure the reliability of the stockpile although admitting that outside access to data on the state of French weapons makes it difficult precisely to evaluate French arguments in favour of testing.

But many suspect that France is developing tactical warheads. Indeed, although the government says that its policy of nuclear deterrence remains unchanged, some parts of the French military argue that variable-yield designs are needed, including weapons with lower yields. But one senior military official, who supports this position, argues that the aim is not to develop battlefield weapons, but to provide a deterrent more suited to the post-ColdWar geopolitical situation.

D. B.

\section{IMAGE UNAVAILABLE FOR COPYRIGHT REASONS}

Japanese demonstrators: should concerns focus on maximum levels for tests rather than France's plans to resume testing?

dismay by non-nuclear states, which see them as evidence that the P5 states are not genuinely committed to a comprehensive test-ban. India, the de facto leader of the non-aligned states, has retaliated by proposing that the treaty should ban all tests involving fissile material, which would even outlaw HNEs with yields of only a few kilograms.

India's proposal represents a hardening of the position of the non-nuclear states. Until recently, these seemed ready to accept not only $1.8-\mathrm{kg}$-yield HNEs, but also a request by Russia that HNEs of up to 10 tonnes should be allowed. Russia has difficulty controlling HNEs, and its case for what is often referred to as a 'whoops factor' has been widely accepted as justified.

According to Rebecca Johnston, the Geneva representative of the London-based Verification Technology Information Centre (VERTIC), India is sending a "strong signal to the nuclear weapons states that if they do not agree to a comprehensive test ban, there will be no test ban at all".

Johnston claims that non-nuclear states have hardened their positions because they feel the P5 have failed to respect the "gentlemen's agreements" given to win their consent to the NPT. The ink on the NPT had barely dried, she points out, before China exploded a bomb, France announced its decision to resume testing, and the United States reopened the debate over thresholds.

Speaking at Geneva earlier this month, Boutros Boutros Ghali, the secretary general of the United Nations, warned that failure to reach agreement quickly on nuclear 
testing would "undermine" efforts by the international community to achieve disarmament. "The question of the threshold is a much bigger issue than the French decision to carry out eight more tests", says Patricia Lewis, head of VERTIC.

Conventional nuclear weapons could not be tested fully within the proposed threshold of 500 tonnes. But such tests would provide nuclear weapons states with data that would give them added confidence in a new design, says Lewis.

She adds that the thresholds being proposed are in the range that is "crucial for weapons design work". In a recent report, the NRDC also argued that such thresholds would allow study of thermonuclear fusion, and the yield of new "boosted" fission designs.

In a curious twist in the dispute over the scope of the CTBT, a senior military official said last week that if France is allowed to carry out its planned tests in the South Pacific, it would back down on its demand that low-yield tests be exempt from the CTBT.

"If France goes ahead with the tests it will not demand a threshold in the CTBT," he says. "We are willing to drop the threshold as a gesture of self-restraint aimed at helping international cooperation."

His remarks are consistent with comments attributed to Jacques Bouchard, the head of the military applications division of the French Atomic Energy Commission (CEA), in a report by the NRDC and the Federation of American Scientists (FAS), a Washington-based lobby group. Bouchard was quoted as having said last year that "the alternative to France conducting a series of nuclear tests would be to insist on a CTBT that would allow tests of at least 100 tons".

Declan Butler

\section{Physicists reveal glimpses of Japan's atomic bomb effort}

Tokyo. As the fiftieth anniversary of the end of the war in the Pacific approaches, details are beginning to emerge of the little-known efforts by Japanese scientists to develop an atomic bomb during the Second World War.

Tatsusaburo Suzuki, an 83-year-old former researcher who was sent by a military institute in 1944 to work on the project at the Institute of Physical and Chemical Research (RIKEN), told a press conference in Tokyo last week that Japan had the necessary expertise to build the bomb but lacked sufficient resources.

"Towards the end of the war, some experts thought it would take us about 100 years to build the bomb," he is reported to have told the Tokyo meeting. "I was of the opinion that if we spent 100 times more in research efforts, we could have developed the bomb in one year."

According to a leading Japanese physicist who was a student at Osaka University during the war, there were three groups in Japan working on what was called the 'uranium bomb'. One group at RIKEN was headed by the institute director, Yoshio Nishina, an eminent nuclear physicist who had studied under Niels Bohr in Denmark. A second group at Osaka University was led by Seishi Kikuchi, another eminent physicist. A third group was at Kyoto University.

Two approaches were pursued, the electromagnetic separation of uranium 235 and separation by a thermal diffusion process. For the second of these, Kikuchi's group at
Osaka built a tall double pipe system extending through several floors of the building. But it was not very successful, and according to one member of the group, it switched to research on a high-powered magnetron before the end of the war.

Very little is known about the research carried out at RIKEN. All records were destroyed after the war, and a spokesman for the institute says "we have no materials". But it is known that the institute was the target of US bombing raids because of its work on nuclear research, and that it suffered severe damage during a raid in April 1945.

But most Western experts conclude that Japan was far behind the United States, Great Britain and Germany in attempting to develop a bomb.

Nevertheless, even after the war RIKEN suffered badly for its war-time efforts. In November 1945, engineers from the US occupation forces dismantled two cyclotrons at the research institute and dumped them in Tokyo Bay. Cyclotrons at Kyoto and Osaka universities suffered similar fates. This was a major setback for Japan's highenergy physics research from which it took decades to recover.

In theory, the cyclotrons could have been used to separate uranium isotopes. But in practice they would have been unable to produce sufficient quantities for a bomb, and the cyclotron destruction was widely condemned by the US high-energy physics community at the time. David Swinbanks

\section{Congress saves Cassini, but targets infrared astronomy mission}

Washington. Only eight days after its threatened demise, the international Cassini mission to Saturn was rescued last week in the US Congress, as the House of Representatives Appropriations committee restored the project's full funding request of \$249 million for 1996.

The committee also reversed a subcommittee's decision to close three field centres belonging to the National Aeronautics and Space Administration (NASA) (see Nature 376, 203; 1995), and called for an agency restructuring study instead. But the Mission to Planet Earth and the proposed Space Infrared Telescope Facility (SIRTF) both suffered budget cuts as NASA rides a roller-coaster through the congressional appropriations process.

In restoring the Cassini money deleted by a subcommittee, the full committee acknowledged the project's importance and virtually ensured that it will remain on track for a 1997 launch. But the money had to come from somewhere, and the committee therefore took $\$ 339$ million out of a \$1.34-billion request for Mission to Planet Earth, which includes the Earth Observing System (EOS).

It also reduced the budget for the airborne SOFIA infrared astronomy programme by nearly half, to $\$ 28.7$ million. While the Gravity Probe-B relativity experiment received full funding at $\$ \mathbf{5 1 . 5}$ million, SIRTF was given no money for next year. NASA had asked for $\$ 15$ million to continue studying the project in 1996, with spacecraft development to begin in 1998 and launch planned for 2002 .

The House Science committee, chaired by Robert Walker (Republican, Pennsylvania), which produced a NASA authorization bill last week, also recommended scaling back EOS and deleting SIRTF funds in 1996. According to staff members, the committee's intention is not to kill SIRTF but merely to delay it until funds become available as other expensive missions such as Cassini get closer to their launch dates.

The project is seen as the infrared entry in NASA's suite of 'great observatories'. These include the Hubble Space Telescope, the Compton Gamma Ray Observatory and the Advanced X-Ray Astrophysics Facility (AXAF). Advisory committees from the National Academy of Sciences have consistently given SIRTF high priority among proposed astronomy projects. But its high cost (\$560 million), its lack of international participation and the fact that it is not yet under way has made it a tempting target for budget-cutters.

According to NASA managers, without the $\mathbf{1 9 9 6}$ money the launch would slip by a year, and some of SIRTF's scientific return would be compromised, as it would not be able to conduct as many coordinated observations with other space observatories. A launch in 2003 would miss most of the opportunity to overlap with the Hubble Space Telescope, as well as any overlap with AXAF.

Tony Reichhardt 